

\title{
Kaddish, Sinfonía núm. 3
}

\author{
Kaddish, Symphony No. 3
}

\author{
LEONARD BERNSTEIN \\ Introducción, traducción y notas de Adriana Menassé \\ Introduction, Translation and Notes by Adriana Menassé
}

RESUMEN: Primera traducción al español, acreditada por la Leonard Bernstein Office, Inc., del recitativo que estructura la Tercera sinfonía de Bernstein llamado "Kaddish". El kaddish es uno de los rezos más entrañables de la tradición judía, una oración por los muertos donde curiosamente no hay referencia a la muerte, sino a la gloria de Dios. En el texto de Bernstein, sin embargo, el doliente se dirige a Dios y lo confronta con dureza, pero tal querella le permite reencontrarse y reconciliarse con Él, exigirle, así, un nuevo pacto.

Además de la traducción, se ofrece una lectura filosófica que aborda las resonancias de significado implícitas en el texto del Orador y que dan cuenta, sin duda, del gran poder emotivo de la obra.

Abstract: This is the first translation into Spanish, acknowledged and credited by the Leonard Bernstein Office, Inc., of the Speaker's part - the prayer form running throughout Bernstein's Third Symphony called Kaddish. Kaddish is the most heartfelt prayer in the Jewish tradition, a prayer for the dead where no reference is made to death itself but to the glory of God. In Bernstein's version, however, the Speaker confronts God harshly but only to reassert the bond between them and demand a new covenant.

Accompanying the translation, I offer a reflective reading of the echoes with which the words are infused and which account for the text's emotional power.

Palabras Clave: orador, Dios, confrontación, pacto.

KEYWORDS: prayer, God, confrontation, harmony, covenant.

RECIBIDO: 9 de marzo de 2017 • ACEPTADo: 21 de junio de 2017 



\section{Introducción de la traductora}

\section{El Dios de Bernstein y el Dios de Job}

"Kaddish", el título que da nombre a esta tercera sinfonía de Leonard Bernstein, remite a uno de los rezos más solemnes del rito judío: la oración para los muertos. Aunque sus líneas se recitan en distintos momentos de la liturgia e incluso entre sus partes, cobra todo el peso de su significado como oración del doliente por sus seres queridos, y así se le reconoce normalmente. Se ha señalado, con razón, que esta oratoria luctuosa no menciona nunca la muerte, sino la gloria de Dios. Se dice kaddish para que, en medio del dolor de una pérdida, tengamos presente la grandeza de la vida y encontremos consuelo en ese recordatorio. "Yitgaddal veyitqaddask shmeh rabba". "Sea Su gran nombre exaltado y santificado/en el mundo que Ha creado según Su voluntad [...]".

El kaddish es un rezo en arameo; como algunos otros de la tradición judía, ha de recitarse siempre en colectivo, es decir, requiere diez hombres (un minyan) para poder decirlo o, en ocasiones, cantarlo. Así, por definición, una oración solitaria no es un kaddish. Sin embargo, por la intensidad del sentimiento que emerge en los momentos más vulnerables como es el de una pérdida hondamente sentida, existen variaciones de este rezo que abren la posibilidad de una conexión personal y directa con Dios. El kaddish lo recitan los hijos por los padres, los esposos por sus cónyuges, los hermanos entre sí o los padres por sus hijos. Pero cualquier miembro de la comunidad puede decirlo — ha de decirlopor aquel que no tiene quién le rece.

Es probable que Leonard Bernstein tuviera en mente esta forma de la oración (kaddish yahid o kaddish individual) cuando escribió la parte recitada de su sinfonía: es más un estado de concentración dialógica que un kaddish en sentido estricto, pero la voz del Orador, la línea temática y narrativa que propiamente estructura la pieza musical, contiene evocaciones del Libro de Job. Se trata de una conversación con Dios, o digamos de una confrontación directa con el Altísimo: en medio de la música, del solo de la soprano y los coros de niños que repiten las bendiciones y las alabanzas del rezo, el hombre solitario en su dolor se 
pregunta y se indigna contra Dios por el sufrimiento y la injusticia del mundo. Como se sabe, Bernstein le dedicó su Sinfonía núm. 3 a John F. Kennedy, tras el impacto que le produjo su asesinato poco antes de que se estrenara la obra en $1963 .{ }^{1}$ El texto, sin embargo, remite, aunque no de manera explícita, al impensable horror del Holocausto, y a las tantas y tantas víctimas de la crueldad y la necedad humanas.

Así lo entiende y así lo expresa Samuel Pisar cuando el mismo Bernstein, su amigo, le pide que enriquezca su texto con el suyo - testigo como era del Espanto - con la fuerza de su experiencia, de su diálogo y su imprecación a Dios, después de haber sobrevivido a Auschwitz, Sachsenhausen y Dachau. Y en verdad el texto de Pisar enfrenta a Dios con lo innombrable, y aunque no deja de tener momentos estremecedores (cuando confiesa, por ejemplo, la imposibilidad de afirmar Su gloria en medio de aquella destrucción sistemática y atroz), el texto de Bernstein parece animado por una intuición teológica más penetrante y luminosa. ${ }^{2}$

El tono en que habla el Orador en la Sinfonía núm. 3 de Bernstein expresa de manera ejemplar la modalidad del diálogo con Dios que en la tradición judía toma una forma característica. Es un diálogo muy íntimo, que en ciertos casos hasta podría parecer descomedido; una conversación de viejos amigos, tan queridos que admite reproches y cuestionamientos, incluso vehementes, pero sólo para volver a establecer el puente de amor que reclama la verdadera cercanía. En este caso, la

$C f$. https://leonardbernstein.com/about/humanitarian/an-artists-response-to-violence; consultado por última vez el 26 de mayo de 2017.

2 Según fuentes cercanas a la familia, poco antes de su muerte Bernstein pidió a su amigo Samuel Pisar, sobreviviente del Holocausto, que hiciera un texto donde incluyera su propia terrible experiencia en el diálogo desesperado que entonces estableciera con Dios, y que serviría para darle cuerpo a la voz del Orador. El texto de Pisar se incluyó en la Sinfonía y, por lo general, él recitaba esa parte. Sin embargo, a la muerte de Pisar, se vuelve al texto original. Gracias a una tía francesa que lo rescató y lo llevó a París y luego a Australia, Samuel Pisar retomó sus estudios y eventualmente viajó a Estados Unidos. Allí se convirtió en un reconocido abogado, en asesor económico del gobierno de Kennedy y en comprometido colaborador de la Unesco para cuestiones de educación. Pisar escribió un par de libros que le merecieron reconocimientos, entre los que destaca Of Blood and Hope, traducido al español como La sangre de la esperanza. $C f$. www.unesco.org/fileadmin/MULTIMEDIA/HQ/ERI/pdf/S.Pisar-Biography.pdf; consultado por última vez el 26 de mayo de 2017. 
alabanza del rezo se contrapuntea con la voz del Orador que, un poco a la manera de Job, confronta a Dios y le requiere por el gran sufrimiento que ha de padecer el ser humano. A diferencia de Job, sin embargo, Dios no responde ni aparece. O digamos, aparece tan sólo en la inquebrantable voluntad del hombre de renovar el pacto, de renovar el pacto de confianza que los uniera, de establecer, así, un nuevo pacto. No son los viejos patriarcas los que se dirigen a Dios ahora: es el hombre del siglo xx, desencantado, que ha debido atravesar el infierno y sabe que no puede esperar salvaciones mágicas. Como dice el propio Bernstein, el nuevo pacto que el Orador le ofrece, que le exige, a Dios, no se plantea desde la inocencia del niño pequeño y desvalido que ve en su padre la fuente de protección y vida, sino de otro modo, desde el reconocimiento de una dependencia mutua, y, por lo tanto, de la atadura que los constituye a ambos. "Sufrimos y nos recreamos uno al otro", dice el Orador en el tope de su potencia expresiva; "sufrimos y nos recreamos uno al otro", punto culminante, si no de la música, sí de la lírica en una apuesta que es compromiso y esperanza.

Pero, ¿por qué habría el ser humano de renovar el pacto después de toda una historia de crueldad e insensatez, donde el Altísimo no parece haber tenido ninguna participación a favor de víctimas inocentes? ¿Por qué renovar un pacto roto, atravesado de incomprensión, traición mutua, impiedad y escepticismo? El texto se refiere, sin duda, al pacto que establece Dios con Israel, un Israel que en cierto nivel remite a un pueblo específico, pero que, sobre todo, representa a la humanidad en su conjunto. ¿En qué consiste dicho "pacto", por cierto?, ¿de qué está hecho? Le pregunta a Dios el Orador: “¿Por qué has ocultado tu arco iris/Ese bonito lazo que atabas a Tu dedo/Para acordarte de no olvidar nunca Tu promesa?"

El pacto de Israel con Dios es aquel en que Israel (el ser humano) se obliga a obedecer los mandamientos. Mandamientos de justicia y de paz, de amor al prójimo y cuidado del huérfano y la viuda. ¿A cambio de qué? A cambio de la "protección de Dios", es decir, de la confianza que establece entre nosotros, de la paz misma y la armonía que provienen de dicho cumplimiento. Si se cumplen los mandamientos reina la paz, si se rompen sobrevienen la injusticia, la dureza y la apatía. Entonces la vida muestra la mueca de su vacío. 
Pero también sabemos que la creación y la grandeza de Dios exceden la relación de Dios con la criatura humana; la creación es más grande que la constitución ética de la vida humana, si bien la contiene. La magnificencia del mundo es inconmensurable con el sufrimiento del hombre, como mostrara desde antiguo el mismo Libro de Job. Por tanto, la protección de Dios no está garantizada; está apenas presupuesta, sugerida. El mandamiento ha de servirnos a nosotros y sólo indirectamente a Él, en la medida en que nos permite sostener el amor en el mundo, sostener la confianza que hace la vida digna y hermosa, merecedora de nuestro agradecimiento y alabanza. El pacto - el mandato de sostener el orden ético en el que acontece la vida humana - es el asentimiento al que otorgamos nuestra lealtad, en el que nos jugamos una fe primaveral y una alegría de base. "El universo se sostiene sobre un hombre justo", dice el Talmud. ${ }^{3}$ Sostener con nuestros actos, día a día, el pacto de humanidad, generosidad y escucha; sostenerlo en las pequeñas cosas, los pequeños gestos de responsabilidad y desprendimiento es acaso todo lo que podemos hacer, todo lo que nos corresponde hacer en nuestro viaje. Pero es al mismo tiempo una enormidad, la enormidad del lazo que nos hace humanos y que continuamente renovamos o destruimos.

El llamado de la Altura, dice Emmanuel Levinas, el llamado del Otro que se presenta a mí como un rostro desnudo, instituye el vínculo a partir del cual el lenguaje sobreviene como respuesta: "Aquí estoy". ${ }^{4}$ En el lenguaje bíblico Abraham e Isaías responden "heme aquí". "Heme aquî" representa la disposición de hospitalidad anterior al diálogo, anterior a toda petición explícita, porque es la que inaugura la posibilidad misma de comprendernos. Este vínculo "pre-originario", dice Levinas, puesto que está antes de todo principio, articula simultáneamente la relación con nuestros prójimos y con eso que, como dice Gilberto Owen,

3 Sobre treinta y seis hombres justos se sostiene el mundo según el Talmud, pero cada uno de nosotros lo sostiene igualmente y ayuda a recrearlo con actos de amor y compasión. O lo destruye a través de la impiedad y la dureza de corazón. $C f$. Sanhedrín 97b, Sucá 45b, "sobre los Tzadikim Nistarim".

$4 \quad$ Esta visión levianasiana, es decir, que en el rostro de mi prójimo se manifiesta la exigencia de responsabilidad de donde nace la ética, recorre el pensamiento del autor como su leit-motif. Puede encontrarse en su obra más acabada, Totalidad e infinito, pero se encuentra igualmente en Ética e infinito, De Dios que viene a la idea, De otro modo que ser y, de hecho, a lo largo de toda su producción. 
"por comodidad llamamos simplemente Dios". ${ }^{5}$ El imperativo que brota de la fractura desde la que me habla mi prójimo, no es mera compasión ni apela a la misericordia; es, ante todo, una exigencia, el apremio que nace de su desvalimiento y que al llegar a mí como exhortación, inaugura para ambos el orden del sentido. Criatura, semejanza de Dios, el ser humano entra en contacto con la Altura, a través de sus semejantes. Y sólo alcanza a estrechar a sus semejantes bajo el abrigo de Dios. Dios habita el espacio en que nos encontramos.

Acaso sea esta la intuición más radical del texto de Bernstein, la dependencia mutua y mutua determinación de Dios y el Hombre. El ser humano se constituye en su vocación de amor y de sentido; en su búsqueda de la bondad y la justicia, en su apertura al otro, pues esa apertura misma es el puente que establece con la trascendencia, es su apuesta ciega por la belleza del mundo. La vida cobra sentido humano como despliegue de dicha vocación. "Dios" no ocurre como objetividad ajena al diálogo; tampoco es una mera invención del sujeto. Es la relación la que lo revela; es la dimensión del amor y la inocencia, de la gratitud y el deseo de justeza y armonía, donde la presencia divina se manifiesta en su gracia. Renovar el pacto es volver a confiar. Es estar dispuesto, como el santo Job, a aceptar la grandeza del mundo y su misterio, incluso por encima del dolor o el sinsentido. Y volver a amar, y volver a regocijarse y a ofrecer su adhesión a lo que nos guía y nos sostiene.

Recrear el vínculo; ya no es sólo el hombre el que confía en Dios, sino Dios el que es conminado a confiar en el hombre, a creer que éste será capaz de llevar adelante la tarea conjunta de "completar la creación" llenando el mundo con buenas acciones, con su amor y su anhelo de equidad, y el deseo de suavizar en su alma las costras de rigidez o resentimiento para volver a bendecir y agradecer.

Es ésta, me parece, la apuesta de Bernstein, la propuesta de su magnífico Orador, el hombre que en la intimidad de su rezo se dirige al Altísimo como a un Padre amoroso pero falible, un Maestro luminoso y vulnerable de quien toma su fuerza y a quien recurre como guía. Cree en mí, le ruega, cree en mí. Cree en mí pues en esa fe me veo y en ella me hago digno de nuestro lazo.

5 De su poema “Teologías”, publicado en su libro Línea en 1930. 
Y digamos entonces amén, que así sea.

Presento aquí la traducción del texto del Orador; éste se va intercalando a lo largo de la Sinfonía con base en las distintas partes del rezo. La traducción tiene su centro en el tono íntimo de la conversación directa y cercana con Dios que permea el vínculo de la relación con el Altísimo en la tradición rabínica. He intentado conservar la sencillez y la emotividad de dicho lazo, manteniendo, al mismo tiempo, el tono litúrgico de la plegaria y aun la altura filosófica de la confrontación. Como se verá, el rezo y su tono laudatorio se van entrecruzando y por momentos contrapunteando con el discurso del orador. He tratado de mantener la forma directa, oral, de los versos en inglés, así como mostrar con claridad la potencia afectiva de su propuesta teológica. 


\section{LEONARD BERNSTEIN}

Kaddish, Sinfonía núm. 3

\section{ORADOR:}

\section{INVOCACIÓN}

Padre mío, antiguo, venerado

Abandonado y triste Padre:

Engañado y desmentido Rey del Universo:

Vieja Majestad irritada y marchita:

Quiero rezar.

Quiero decir kaddish.

Mi propio kaddish. Tal vez no haya nadie

Que pueda hacerlo después de mí.

Tengo tan poco tiempo, como sabes.

¿He de morir en un minuto, en una hora?

¿Hay tiempo, siquiera, de considerar el asunto?

Podría ser que en este lugar mismo, mientras cantamos,

Detengan nuestro paso de una vez por todas,

Nos corten de raíz en el acto de alabarte.

Pero mientras tenga aliento, por más breve que sea,

Cantaré para Ti este último kaddish,

Para mí y para todos estos a quien amo

En esta casa sagrada. 
Quiero rezar, y hay poco tiempo.

Y it'gadal v'yit Kadesh sh'me raba...

\section{KADDISH I}

ENALTECIDO... Y SANTIFICADO... SEA EL GRAN NOMBRE... AMÉN

CORO: (Traducción. No se canta)

Enaltecido y santificado sea Su gran nombre, Amén

A lo ancho del mundo que ha creado según Su voluntad, Amén.

Y sea Su reino establecido

En el tiempo de tu vida y de tus días

Y en los días de todo el pueblo de Israel,

Cuanto antes, en el futuro cercano,

Y digamos Amén.

Y sea Su gran nombre bendito

Por siempre y para toda la eternidad.

Santificado y alabado, glorificado

Exaltado y elogiado, venerado

Y enaltecido y celebrado

Sea el nombre del Santo, bendito sea;

Aunque Él esté más allá de todas las bendiciones

Himnos, alabanzas y consuelos

Que sean en el mundo proferidos,

Y digamos, Amén.

Séanos concedida paz del cielo

En abundancia, y vida para nosotros

Y para todo Israel;

Y digamos, Amén.

ORADOR:

¡Amén! ¡Amén! ¿Escuchaste eso, Padre? 
i"Sh'lama raba! Que paz en abundancia

Descienda sobre nosotros. Amén.

Gran Dios,

Tú que pones paz en las alturas

Que gobiernas los días desde el principio de los tiempos,

Y dispones que la aurora conozca su sitio

Podrías, seguramente, causar y disponer

Una pizca de orden aquí abajo

En éste, nuestro azorado grano de polvo.

Y digamos otra vez: Amén.

\section{II}

DIN TORAH

\section{ORADOR:}

Con Amén en los labios me acerco

A tu presencia, Padre. No con temor,

Sino con cierta rabia reverente.

¿No reconoces mi voz?

Soy la parte del Hombre que Tú hiciste

Para mostrar su veta eterna

Seguramente lo recuerdas, Padre - la parte

Que rechaza la muerte e insiste en tu amor.

Que adivina tu voz, que infiere tu gracia.

Y Tú siempre escuchaste mi llamado

Y Tú siempre respondiste

Con un arco-iris, un cuervo, una plaga, algo.

Pero ahora no veo nada. Esta vez no me muestras

Absolutamente nada.

¿Me escuchas Padre? Bien sabes quien soy:

Tu imagen, ese obstinado reflejo de Ti

Que el Hombre ha destrozado, suprimido, desterrado.

Y ahora corre libre - libre para jugar 
Con su fuego recién descubierto, ávido de muerte,

De la voluptuosa, completa y absoluta muerte.

Señor, Dios de los Ejércitos, ¡te llamo a rendir cuentas!

¡Tú permitiste que esto sucediera, Rey de los Ejércitos!

¡Tú con tu maná, tu columna de fuego!

¿Pides que tenga fe? ¿Dónde está la Tuya?

¿Por qué has ocultado tu arco iris,

Ese bonito lazo que atabas a tu dedo

Para acordarte de no olvidar nunca tu promesa?

"Pues ved, he puesto mi arco entre las nubes

Y cuidaré de él que me sea recuerdo

Del pacto que he establecido para siempre..."

¡Tu pacto! ¡Tu contrato con el Hombre!

¡Dios de hojalata! ¡Tu contrato es de hojalata!

Se abolla entre mis manos

¿Y qué es de la fe ahora — de la mía y de la tuya?

CORO: (Cadenza)

Amén, Amén, Amén...

\section{ORADOR:}

Perdóname, Padre. Deliraba con fiebre.

¿Te lastimé? Perdóname.

Olvidé que también Tú eres vulnerable.

Pero fue tuyo el primer error, crear

Al hombre en tu imagen, débil

Falible. Dios querido, cómo debes sufrir,

Tan lejos, mirando con tristeza

Tu obra de dos piernas - frágil, insensata, Mortal. 


\section{KADDISH 2}

\section{ORADOR:}

Padre afligido.

Si pudiera consolarte, tenerte en mi regazo

Arrullarte y mecerte hasta que duermas.

SOPRANO SOLO y CORO DE MUJERES:

Enaltecido y santificado sea Su gran nombre, Amén

A lo ancho del mundo que ha creado según Su voluntad, Amén.

Y sea Su reino establecido

En el tiempo de tu vida y de tus días

Y en los días de todo el pueblo de Israel,

Cuanto antes, en el futuro cercano,

Y digamos Amén.

Y sea Su gran nombre bendito

Por siempre y para toda la eternidad.

Santificado y alabado y glorificado

Exaltado y elogiado y venerado

Y enaltecido y celebrado

Sea el nombre del Santo, bendito sea;

Aunque Él esté más allá de todas las bendiciones

Himnos, alabanzas y consuelos

Que sean en el mundo proferidos,

Y digamos, Amén.

Séanos concedida paz del cielo

En abundancia, y vida para nosotros

Y para todo Israel;

Y digamos, Amén.

Él, que hace paz en las Alturas,

Haga paz para nosotros

Y para todo Israel;

Y digamos, Amén. 
ORADOR:

Descansa Padre mío. Duerme, sueña.

Déjame inventar tu sueño, soñarlo

Contigo, lo más dulcemente que pueda.

Y quizás en sueños ayudarte

A recrear tu imagen, y a amarla de nuevo.

\section{III}

SCHERZO

\section{ORADOR:}

Te llevaré a tu estrella favorita

El mundo más digno de tu obra

Y tomados de la mano, veremos con asombro

Los mecanismos de la perfección.

Este es tu Reino Celestial, Padre,

Tal como lo planeaste.

Todo cliché inmortal en su lugar.

Los corderos retozan. El trigo se eleva.

Los rayos del sol bailan. Algo está mal.

La luz: sin brillo. El aire: estéril.

¿Sabes qué falta? No hay nada que soñar.

No hay adónde ir. Nada que saber.

Y éstas, criaturas de tu Reino,

Esta gente sonriente, serena, insensible

¿Han sido igualmente creadas a tu imagen?

Tú eres serenidad, pero también furia.

Lo sé, he debido sufrirla.

Eres esperanza, pero también arrepentimiento.

Lo sé. De mí te has arrepentido.

Pero no éstos - los perfectos:

Ellos están más allá del arrepentimiento, o la esperanza.

No existen, Padre, ni siquiera

En los años-luz de nuestro sueño. 
¡Déjame enseñarte ahora un sueño que no olvides!

Regresa conmigo a la Estrella del Arrepentimiento:

Regresa Padre, a donde el sueño es verdadero,

Y el dolor es posible - tan posible

Que tendrás que creerlo. Y en el dolor

Reconocerás tu imagen finalmente.

¡Ahora contempla mi Reino en la Tierra!

¡Verdaderos prodigios! ¡Maravillas auténticas!

¡Deslumbrantes milagros!

¡Mira, una zarza ardiente!

¡Mira, una rueda de fuego!

¡Un carnero! ¡Una roca! ¿La golpeo? ¡Mira!

¡Brota el agua a borbotones! ¡Y yo lo hice!

¡Yo estoy creando este sueño! ¿Por fin

Creerás?

Te tengo, Padre, encerrado en mi sueño,

Y deberás quedarte hasta la última escena...

¡Anda! ¡Levanta la mirada! ¡En lo alto! ¿Qué ves?

Un arcoíris, que he creado para Ti

¡Mi promesa, mi pacto!

Míralo Padre: ¡Cree en él! ¡Cree en él!

Contempla mi arcoíris y repite conmigo:

¡ENALTECIDO... Y SANTIFICADO... SEA

EL GRAN NOMBRE DEL HOMBRE!

Los colores de mi arcoíris te deslumbran Padre,

Y lastiman tus ojos, ya lo sé.

Pero no los cierres ahora. No mires a otra parte.

Mira. ¿Ves qué sencillo y sereno

Se vuelve todo cuando crees?

¡Cree, Padre mío!

$¡$ ¡Cree! 


\section{KADDISH 3}

CORO DE NIÑOS:

Yit'gadal v'yit Kadesh sh'me raba, amen.

(Enaltecido y santificado sea Su gran nombre. Amén)

\section{ORADOR:}

No despiertes aún. Por más grande que sea tu dolor,

Yo te ayudaré a soportarlo.

Ah Dios, cree. Cree en mí

Y verás el Reino Celestial

En la Tierra, tal como lo planeaste.

Cree en mí... cree en mí...

Ve cómo mi arcoíris ilumina la escena

Las voces de tus hijos claman

De uno a otro extremo entonando alabanzas.

\section{CORO DE NIÑOS:}

A lo ancho del mundo que ha creado según su voluntad, Amén.

Y sea su reino establecido

En el tiempo de tu vida y en tus días

Y en los días de todo el pueblo de Israel,

Cuanto antes, en el futuro cercano,

Y digamos Amén.

\section{ORADOR:}

El arcoíris se esfuma. Nuestro sueño se acaba.

Debemos despertar ahora; y la mañana es fría.

\section{FINALE}

\section{ORADOR:}

La mañana es helada, pero la mañana asoma. 
Padre, hemos ganado otro día.

Hemos soñado nuestro kaddish y amanecimos con vida.

Buenos días, Padre. Podemos todavía ser inmortales,

Tú y yo, unidos por nuestro arcoíris.

Ese es nuestro pacto, y honrarlo

Es nuestra honra... no exactamente el pacto

Que acordamos hace tanto,

En el tiempo de ese otro, arcoíris primero

Pero entonces yo era sólo tu pequeño hijo indefenso

Abrazado a tu cuerpo, y que sin ti moría.

Ambos hemos crecido, Tú y yo.

No estoy triste y Tú no debes estar triste.

Desarruga tu ceño; míranos de nuevo con ternura

A mí, a nosotros, a todos estos niños

De Dios en esta casa sagrada.

Y nosotros también te miraremos con ternura.

Ah, Padre mío, Rey de la Luz

Amada Majestad: ¡mi ser, mi imagen!

Somos uno solo después de todo, Tú y Yo;

Juntos sufrimos, existimos juntos.

Y por siempre nos recrearemos uno al otro.

¡Nos recrearemos uno al otro!

¡Sufrimos y recrearemos uno al otro!

\section{SOPRANO SOLO, CORO DE NIÑOS Y CORO:}

Sea su nombre bendito

Por siempre y para toda la eternidad

Santificado y alabado y glorificado

Exaltado y elogiado y venerado

Y enaltecido y celebrado

Sea el nombre del Santo, bendito sea;

Aunque Él esté más allá de todas las bendiciones

Himnos, alabanzas y consuelos

Que sean en el mundo proferidos,

Y digamos, Amén. 
Séanos concedida paz del cielo

En abundancia, y vida para nosotros

Y para todo Israel;

Y digamos, Amén.

Él que hace paz en las Alturas

Haga paz para nosotros

Y para todo Israel;

Y digamos, Amén. 